\title{
Orographic control of the Bay of Bengal cold pool rainfall
}

\author{
P V Arushi ${ }^{1,2, *}{ }^{\infty}$, Arindam Chakraborty ${ }^{1,2}$ and Ravi S Nanjundiah ${ }^{1,2,3}$ \\ ${ }^{1}$ Centre for Atmospheric and Oceanic Sciences, Indian Institute of Science, Bengaluru 560 012, India. \\ ${ }^{2}$ Divecha Centre for Climate Change, Indian Institute of Science, Bengaluru 560 012, India. \\ ${ }^{3}$ Indian Institute of Tropical Meteorology, Pune 411 008, India. \\ *Corresponding author.e-mail: arushi@iisc.ac.in
}

MS received 24 February 2017; revised 30 May 2017; accepted 30 May 2017; published online 23 November 2017

In boreal summer (June-September), most of the Indian land and its surroundings experience rainrates exceeding $6 \mathrm{~mm}$ day $^{-1}$ with considerable spatial variability. Over southern Bay of Bengal (BoB) along the east coast of the Indian peninsula (henceforth referred to as the Bay of Bengal cold pool or BoB-CP), the rain intensity is significantly lower $\left(<2 \mathrm{~mm} \mathrm{day}^{-1}\right)$ than its surroundings. This low rainfall occurs despite the fact that the sea surface temperature in this region is well above the threshold for convection and the mean vorticity of the boundary layer is cyclonic with a magnitude comparable to that over the central Indian monsoon trough where the rainrate is about $10 \mathrm{~mm} \mathrm{day}^{-1}$. It is also noteworthy that the seasonal cycle of convection over the BoB-CP shows a primary peak in November and a secondary peak in May. This is in contrast to the peak in June-July over most of the oceanic locations surrounding the BoB-CP. In this study, we investigate the role of the Western Ghat (WG) mountains in an Atmospheric General Circulation Model (AGCM) to understand this paradox. Decade-long simulations of the AGCM were carried out with varying (from 0 to 2 times the present) heights of the WG. We find that the lee waves generated by the strong westerlies in the lower troposphere in the presence of the WG mountains cause descent over the BoB-CP. Thus, an increase in the height of the WG strengthens the lee waves and reduces rainfall over the BoB-CP. More interestingly in the absence of WG mountains, the BoB-CP shows a rainfall maxima in the boreal summer similar to that over its surrounding oceans. The WG also impacts the climate over the middle and high latitude regions by modifying the upper tropospheric circulation. The results of this study underline the importance of narrow mountains like the WG in the tropics in determining the global climate and possibly calls for a better representation of such mountains in climate models.

Keywords. Bay of Bengal cold pool; monsoon; Western Ghats; seasonal cycle; GCM.

\section{Introduction}

The boreal summer monsoon season (JuneSeptember) accounts for more than two-thirds of the annual rainfall over a large domain in south and east Asia extending from the Western Ghat (WG) mountains to the West Pacific Ocean (Wang
2002). Although most of the domain experiences rainfall above $6 \mathrm{~mm}$ day $^{-1}$ in this season, there exists a large spatial variability in its intensity. The windward side of the WG mountains, the northern parts of the Bay of Bengal (BoB), and the warm western Pacific Ocean receive rainfall that exceeds $10 \mathrm{~mm}$ day $^{-1}$. On the other hand, the 
leeward side of the WG mountains, east of the Indian peninsula over south $\mathrm{BoB}$ experiences rainfall $<2 \mathrm{~mm}$ day $^{-1}$. This is in spite of the fact that sea surface temperature (SST) over this region remains above the threshold for tropical convection (Gadgil et al. 1984) and the lower atmospheric vorticity remains positive throughout the season. This region is termed as the Bay of Bengal cold pool $(\mathrm{BoB}-\mathrm{CP})$ in this study.

The region of interest of this study was named because of its relatively cooler SST during the summer monsoon season as compared to the surrounding oceans (Joseph et al. 2005). The low SST over the BoB-CP is mainly because of the cooling associated with the upwelling of the deeper ocean waters due to Ekman pumping (Rao et al. 2006). The wind stress along the shore and the westward propagating Rossby waves radiated by the northward propagating upwelling Kelvin waves off southwest India enhance upwelling along the western boundary of peninsular India during south-west monsoon (Bruce et al. 1994; Shankar and Shetye 1997). This cold waters move along the southern peninsular boundary throughout the season due to oceanic currents and intrude into the Bay of Bengal through BoB-CP (Joseph et al. 2005), contributing to the formation of cold pool. The fluctuations in SST over southern BoB has significant implications in controlling the convection over BoB (Shankar et al. 2007) and is also associated with the activebreak cycle of the Indian Summer Monsoon (ISM) (Joseph et al. 2005).

Several studies have shown that orography plays a key role in determining the climate around the globe (Bolin 1950; Manabe and Terpstra 1974; Meehl 1992; Broccoli and Manabe 1992) including the ISM (Hahn and Manabe 1975). Early pioneering work by Hahn and Manabe (1975) has documented that the absence of global orography reduces early summer monsoon rainfall over south Asia substantially. The importance of the Tibetan plateau as an elevated heat source, which drives the large scale south Asian summer monsoon, has been documented by several researchers (e.g., Ye 1981; Luo and Yanai 1983, 1984; He et al. 1987; Wu and Zhang 1998). However, more recent studies by Chakraborty et al. (2002, 2006) and Boos and Kuang (2010) have shown that the Himalayan orography, especially the western Himalayas, influences the ISM by acting as a mechanical barrier rather than facilitating a thermodynamic heat source.
Apart from the Himalayan mountains, the east African highlands play a significant role in the climate of the western Indian Ocean. They also help in determining the spatial pattern of monsoon rainfall over south and east Asia (Slingo et al. 2005). This is due to the fact that, during the northern summer, easterly winds south of the equator over the Indian Ocean cross the equator and become southwesterly along the eastern side of these mountains (Findlater 1969). These strong winds of the lower troposphere, which are a dynamical response to the latent heating over north BoB (Chakraborty et al. 2002, 2009) and are guided by the east African highlands (Krishnamurti et al. 1976), bring moisture over the Indian region during the summer monsoon. It was shown by Chakraborty et al. (2009) that the absence of the east African orography increases rainfall over Indian land by unblocking surface westerlies from over Africa and, thereby increasing the moisture flux towards south Asia.

The aforementioned surface winds encounter the WG mountains on their way to the Indian subcontinent, which is aligned almost perpendicular to the wind direction. Therefore, it is pertinent to question the role of the WG on the climate of south Asia especially that of the BoB-CP. However, there are only a few studies which address the impact of the WG on the spatial and temporal distribution of rainfall. One of these studies, by Xie et al. (2006), used observations and conducted numerical experiments to interpret the effect of narrow mountains like the WG on climate. Sijikumar et al. (2013) used a regional model to show that presence of WG decreases rainfall over most parts of Bay of Bengal.

In this paper, we study the influence of $\mathrm{WG}$ in determining the climate of the BoB-CP using a global GCM. In the next section, we describe the observational datasets used here. Before presenting our numerical simulations, we document the observed climatology of the BoB-CP in section 3 which sets up the background of our model experiments. Then, we describe the model used and the experiments performed in section 4 . This is followed by detailed results in section 5, remote influence of WG in section 5.5 and a summary of the study in section 6 .

\section{Observational dataset}

The rainfall data was obtained from the Tropical Rainfall Measuring Mission (TRMM) 3B42 
(Huffman et al. 2007) version 7 dataset. This data has a 3 hourly temporal resolution and a $0.25^{\circ} \times 0.25^{\circ}$ spatial resolution. Here, we present the climatology of 1998 through 2014. We also use the Global Precipitation Climatology Project (GPCP) data with a $2.5^{\circ} \times 2.5^{\circ}$ spatial resolution for the period January 1979-December 2011. The circulation parameters like horizontal and vertical winds are obtained from the Modern Era Retrospective Analysis for Research and Applications (MERRA) (Rienecker et al. 2011). The horizontal resolution of this data is $1.25^{\circ} \times 1.25^{\circ}$ and the monthly products used for the analysis are available from 1976 onwards. We also use NOAA OI-SST (National Oceanic and Atmospheric Administration Optimum Interpolation sea surface temperature, Reynolds et al. 2002) version 2 in this study, available at $1^{\circ} \times 1^{\circ}$ resolution.

\section{Observed climatology of the Bay of Bengal cold pool}

We start by showing the observed climatology of June-September rainfall over south and east Asia (figure 1a). A large spatial variability in intensity is evident across the domain. The highest rainfall occurs west of the WG and over the northern parts of $\mathrm{BoB}$. It is to be noted that a large region (marked by a solid blue contour) covering the equatorial Indian Ocean, the BoB, the central Indian land and the west Pacific Ocean experiences a rainrate above $6 \mathrm{~mm}$ day $^{-1}$. The lowest rainfall is seen around $80^{\circ} \mathrm{E}$ and $5^{\circ}-10^{\circ} \mathrm{N}$ latitudes. A large part of this region experiences a rainrate $<2 \mathrm{~mm} \mathrm{day}^{-1}$ (shown as a dotted black contour). This area, however, is surrounded by regions with a relatively larger rainrate. We define this region of low rainrate as a cold pool $\left(3^{\circ}-11^{\circ} \mathrm{N}\right.$ and $\left.77^{\circ}-88^{\circ} \mathrm{E}\right)$, which is identified by a box in figure 1 (c).

The spatial pattern of the climatological SST (figure 1b) of the same period (June-September) shows that most of the domain, including the BoB$\mathrm{CP}$, has a mean SST crossing $28^{\circ} \mathrm{C}$. Gadgil et al. (1984) have documented that there exists a critical threshold of tropical SST for the development of organized convection over oceans. Over the BoB, the critical threshold is about $27.5^{\circ} \mathrm{C}$ (Gadgil et al. 1984; Shenoi et al. 2002). When the SST crosses this threshold value, the presence or absence of convection is closely associated with low level wind convergence (Graham and Barnett 1987). In the case of the BoB-CP, SST is well above the threshold throughout the summer monsoon season (not shown).

Apart from the SST and its spatial gradient, vorticity above the boundary layer is closely associated with convection. A positive value of the vorticity indicates an upward Ekman pumping and hence, ascent. An ascent above the boundary layer induces convection and helps in the formation of clouds. We find that over the BoB-CP, the mean vorticity at $850 \mathrm{hPa}$ during the summer season is positive and its magnitude is comparable to that over the monsoon trough (figure 1c) that receives high intensity rainfall during the summer monsoon season.

In spite of the positive vorticity of the lower troposphere over the BoB-CP, the vertical profile of vertical velocity (figure $2 \mathrm{~b}$ ) shows a descent below
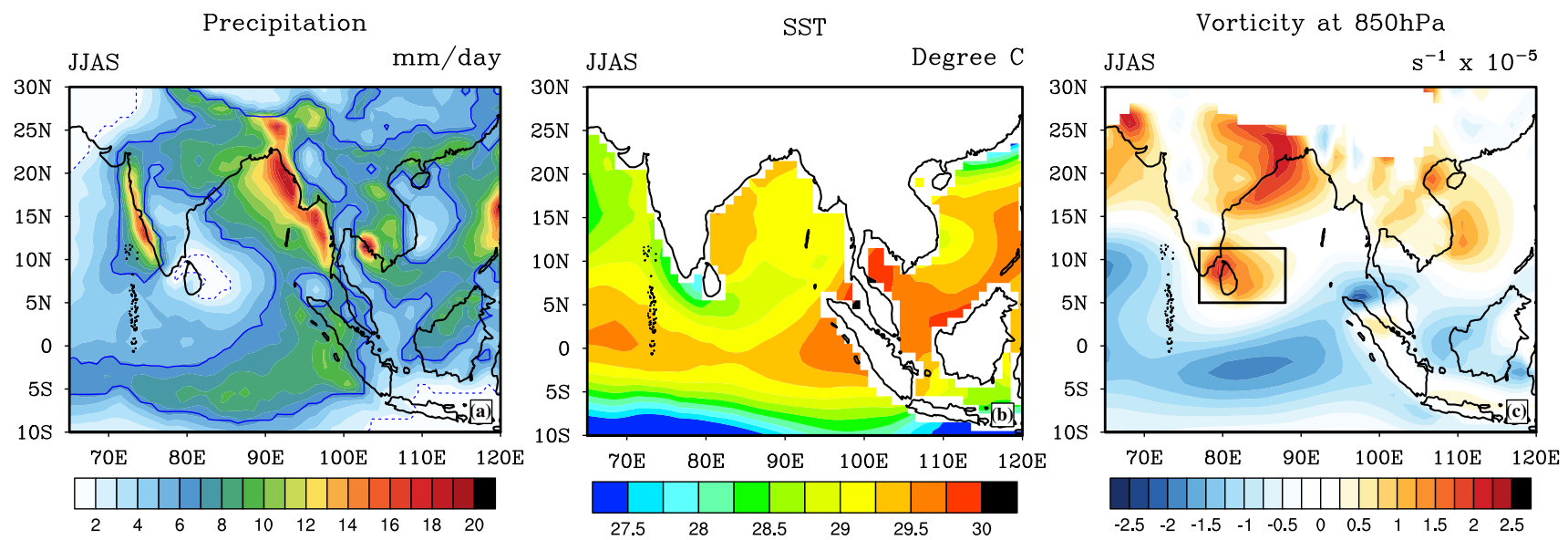

Figure 1. The June-September climatology of (a) rainfall from TRMM 3B42; (b) SST from Reynolds et al. (2002); and (c) vorticity at $850 \mathrm{hPa}$ from MERRA reanalysis. In panel (a), the solid blue line represents $6 \mathrm{~mm}^{\mathrm{day}}{ }^{-1}$ contour and the black dotted line represents $2 \mathrm{~mm}$ day $^{-1}$ contour. In panel (c), we identify the cold pool region by a rectangle. 
JJAS Climatology
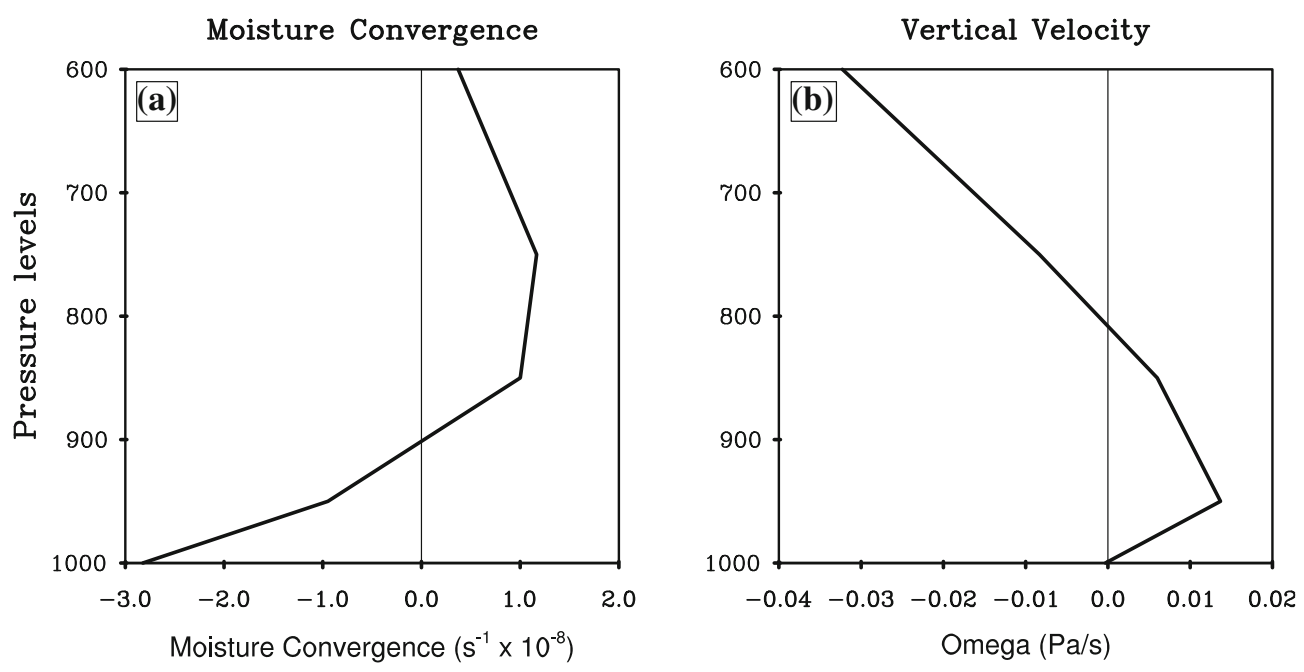

Figure 2. The June-September climatological (1979-2010) vertical profile of (a) moisture convergence and (b) vertical velocity over cold pool from MERRA reanalysis.

the $800 \mathrm{hPa}$ level (We have used pressure vertical velocity which has the unit $\mathrm{Pa} / \mathrm{s}$. Thus negative (positive) sign indicates upward (downward) vertical velocity.). This descent is accompanied by a divergence of moisture below $900 \mathrm{hPa}$ (figure 2a). These conditions result in the overall suppression of convection over the BoB-CP. Similar circulation features prevail over southern peninsular India to the leeward side of the WG (not shown). This is because the moisture-laden surface westerlies hit the WG mountains and precipitate along the windward side. The rain-holding air, after ascending and precipitating over the mountain slopes, becomes dry. The temperature of this dry air increases while descending adiabatically on the lee side of the mountain. Therefore, the descent associated with the WG suppresses the convection over the rain shadow of peninsular India. From figure 1(a), we can see that the BoB-CP, which is situated southeast of the WG, appears to be a continuation of the aforementioned rain shadow; that is, the low rainfall over the BoB-CP could be because it is a part of the rain shadow region. Hence, the suppression of convection over the BoB-CP could be associated with the presence of the WG. However, it is to be noted that the rainfall over the BoB$\mathrm{CP}$ is much lower compared to that over the rain shadow region. This is in spite of the fact that the rain shadow region is much closer to the WG mountains than the BoB-CP.

The aforementioned alternate up-draft and down-draft of the air while flowing across the WG is illustrated in figure 3. The longitude-height cross section of vertical velocity along $8^{\circ}-10^{\circ} \mathrm{N}$ latitudes shows alternate bands of descent (positive) and ascent (negative) suggesting the formation of lee waves (Durran and Klemp 1982; Corby and Wallington 1956). The BoB-CP is situated under a descending branch of this wave. Therefore, these waves may have an important role to play in suppressing convection over the BoB-CP.

Finally, we show the annual cycle of rainfall over the BoB-CP from an observational estimate of the TRMM (figure 4). It can be noted that the annual cycle over the BoB-CP is distinctly different from that over Indian land (InLand: land only region of the domain, $\left.8^{\circ}-28^{\circ} \mathrm{N}, 70^{\circ}-90^{\circ} \mathrm{E}\right)$. There are two peaks in the annual cycle for the BoB-CP, one in May (4 $\mathrm{mm} \mathrm{day}^{-1}$ ) and the other in November (8 mm day ${ }^{-1}$; the primary peak). In contrast, InLand has only one major peak in July-August of about $10 \mathrm{~mm} \mathrm{day}^{-1}$.

Based on these possible associations between the WG and the reduced rainfall over the BoB-CP, we designed numerical experiments to study the influence of the WG in modulating the rainfall pattern over the region.

\section{Model and experimental details}

We used the Global Forecasting System (GFS) model for the present study. This is a spectral model with triangular truncation at 190 waves (T190) which corresponds to about $0.62^{\circ} \times 0.62^{\circ}$ near the equator. It has 64 unequally spaced hybrid 


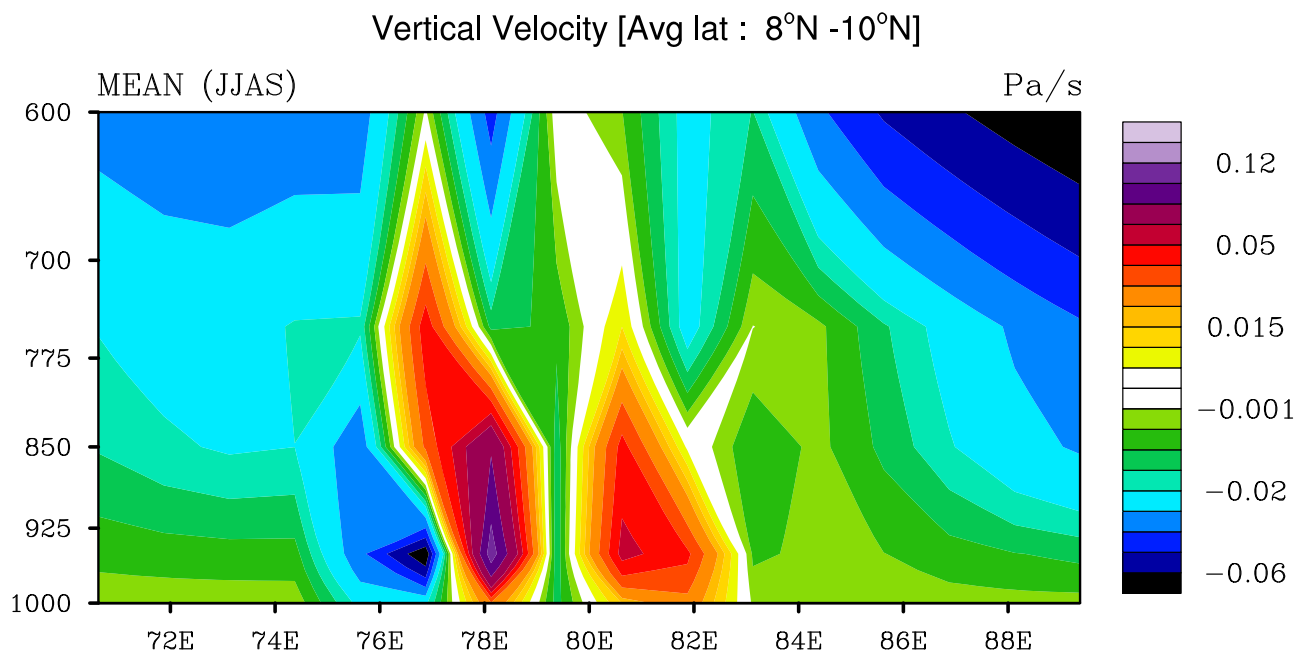

Figure 3. The June-September climatology of vertical pressure velocities from MERRA reanalysis (1979-2010) averaged between $8^{\circ}$ and $10^{\circ} \mathrm{N}$ showing the wave pattern below $700 \mathrm{hPa}$.

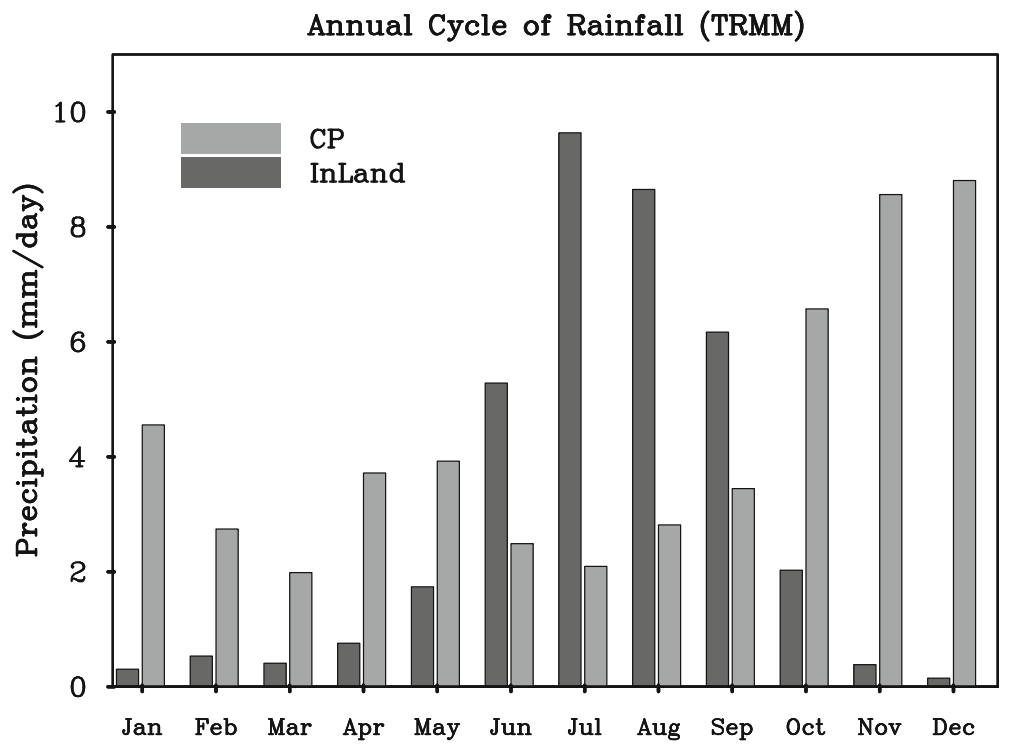

Figure 4. Climatological annual cycle of observed rainfall over Indian land mass (dark gray) and cold pool (light gray).

pressure levels with enhanced resolution near the surface and at the tropopause. In our simulations, we used Relaxed Arakawa and Schubert (RAS) (Moorthi and Suarez 1992) for cumulus parameterization and NOAH Land Surface Model (Ek et al. 2003) for land surface processes. The Rapid Radiative Transfer Model (RRTM) developed at Atmospheric and Environmental Research (AER) (Mlawer et al. 1997) is used for long wave radiation. The short wave radiative transfer parametrization (Hou et al. 2002) is based on the study by Chou (1992), Chou and Lee (1996) and Chou and Suarez (1999). The orography data is taken from the United States Geological Survey (USGS) global digital elevation model (DEM) with a resolution of approximately $1 \mathrm{~km}$ regridded to the model grid. We have initiated the model on 1st January 2008 using the YOTC (Year Of Tropical Convection) analysis product.

Three sets of simulations with varying orographic heights were performed with this model. These are 0WG (no WG mountains), 1WG (WG mountain with its present height; the control run) and $2 \mathrm{WG}$ (WG mountain with twice its present height). All the simulations were carried out over 10 years by initializing the model with YOTC dataset. Since the focus of the present study is to investigate the mean state of the BoB-CP, the model was forced with the monthly climatology of SST interpolated to then model time 


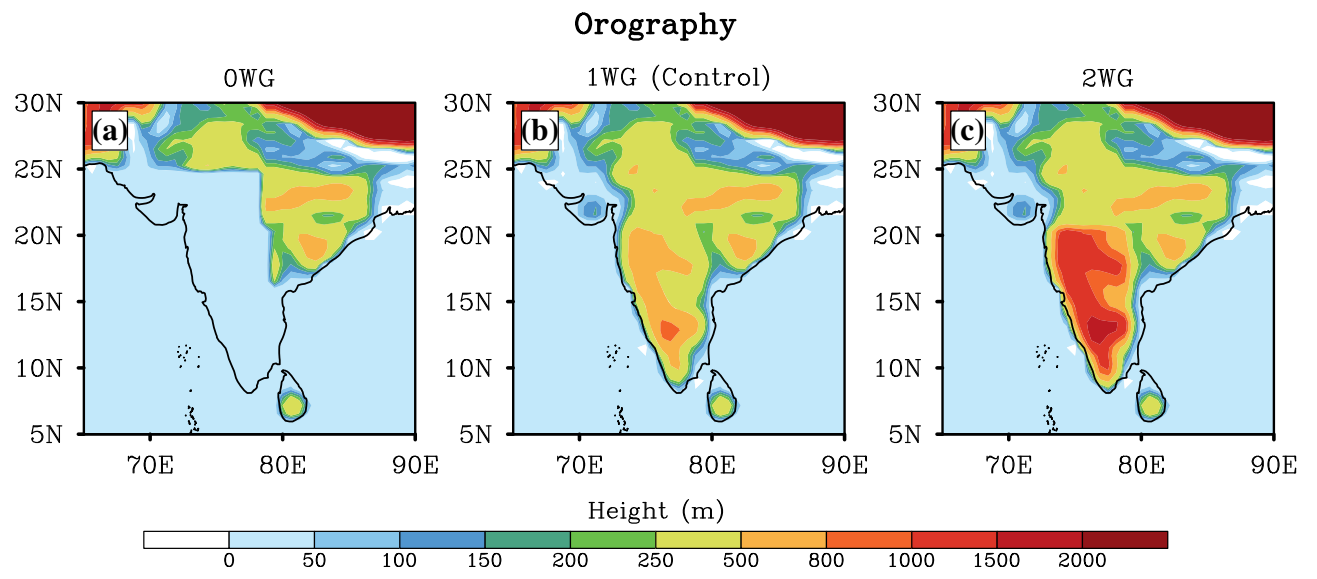

Figure 5. Orographic height over peninsular India prescribed in the three model experiments: (a) No WG mountains (0WG); (b) WG mountain height equal to the present (1WG); and (c) WG mountain height double of the present height (2WG).

Table 1. Nomenclature for different perturbed orography simulations.

\begin{tabular}{llc}
\hline Name & \multicolumn{1}{c}{ Description } & $\begin{array}{c}\text { Length of the } \\
\text { simulation }\end{array}$ \\
\hline $0 \mathrm{WG}$ & $\begin{array}{l}\text { No WG: Orography is removed from } \\
10^{\circ}-16^{\circ} \mathrm{N} \text { and } 79^{\circ}-85^{\circ} \mathrm{E}\end{array}$ & 10 years \\
1WG (control) & $\begin{array}{l}\text { Simulation with mean orography } \\
\text { ThG }\end{array}$ & $\begin{array}{l}10 \text { years } \\
\text { The height of the WG is doubled }\end{array}$ \\
\hline
\end{tabular}

step (Reynolds et al. 2002). This eliminates the possibility of introducing interannual variability with SST forcing. The surface elevation over peninsular India (where perturbations are made) for the three experiments is shown in figure 5. The details of all the experiments are summarized in table 1.

\section{Results}

Based on the observations and the model simulations, we analyze the association between the BoB-CP rainfall with change in height of WG. Here, we diagnose changes in various parameters which will give insight into the prevailing inhibition of convection over BoB-CP.

\subsection{Impact on the summer monsoon}

Figure 6 shows the climatology of the rainrate in June-September over south Asia from model simulations with three different orographic conditions. The high rainrate along the WG and central India is captured well by the control model (1WG; figure $6 \mathrm{~b})$ although there is some degree of underestimation along the WG and overestimation over central India. The model simulates low rainfall over the
BoB-CP. However, the area covered appears to be smaller in the model than in the observation. Owing to this difference between the observed and the model climatology of the rainfall, we define the BoB-CP of the model as that identified by the 'rectangle' in figure $6\left(6^{\circ}-10^{\circ} \mathrm{N}\right.$ and $\left.78^{\circ}-84^{\circ} \mathrm{E}\right)$.

We now address the question of whether the summer monsoon rainfall over the BoB-CP decrease with an increase in the height of the WG. Figure 7 shows the spatial pattern in the difference in JJAS (June-July-August-September) mean rainfall for $0 \mathrm{WG}$ and $2 \mathrm{WG}$ simulations as compared to the $1 \mathrm{WG}$ simulation. After the removal of the WG, there is an increase in rainfall over the BoB-CP and the western coast of the $\mathrm{BoB}$ (figure $7 \mathrm{a}$ ). However, rainfall along the western side of the WG, and the equatorial Indian Ocean decreases with the removal of the mountains. In the 2WG simulation (figure $7 \mathrm{~b}$ ), we notice a reduction in rainfall over the $\mathrm{BoB}-\mathrm{CP}$, north $\mathrm{BoB}$ and south BoB. The rainfall over the north and central peninsular region and over the Arabian Sea has increased. In general, we note that with an increase in the height of the WG, there is an increase in rainfall in the western parts of peninsular India and a decrease in the eastern parts of peninsular India. Despite the variation in the spatial distribution of rainfall over the Indian landmass, the ISMR 

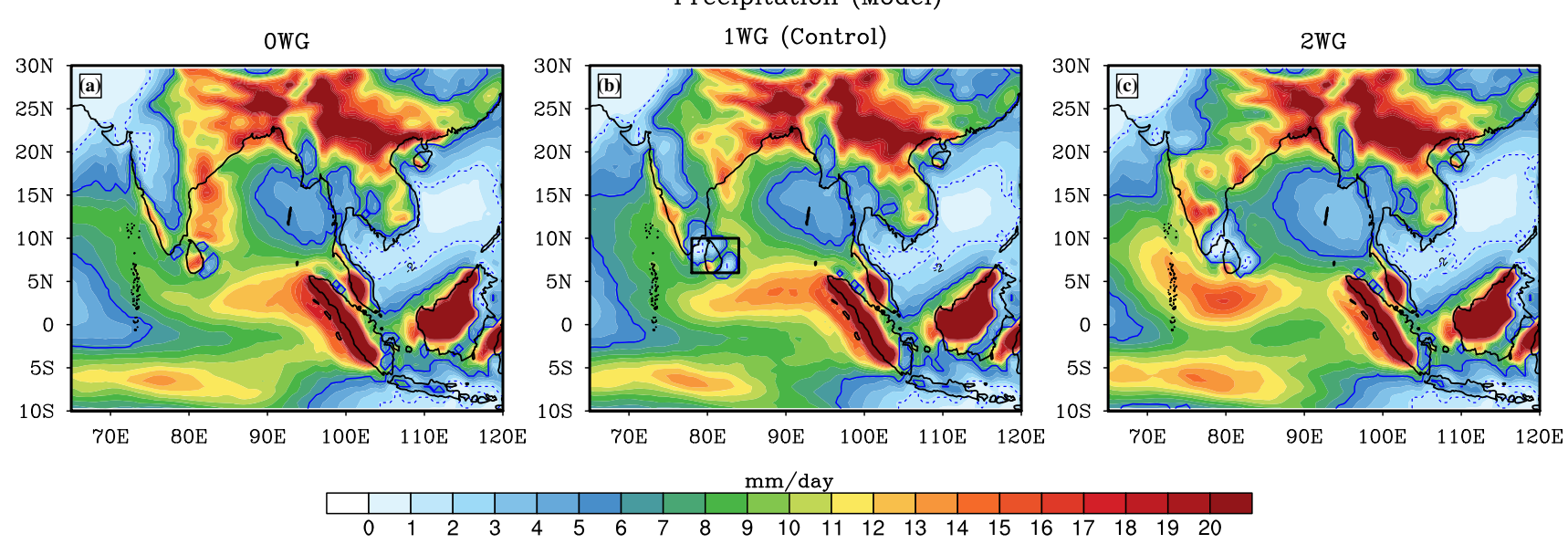

Figure 6. Climatology of the JJAS rainfall for the three different cases: (a) 0WG; (b) 1WG; and (c) 2WG. The cold pool of the model is identified by the rectangle, to be consistent with the model's climatology of rainfall. The blue line represents $6 \mathrm{~mm} \mathrm{day}^{-1}$ contours and the dotted line represents $2 \mathrm{~mm}$ day ${ }^{-1}$ contour.

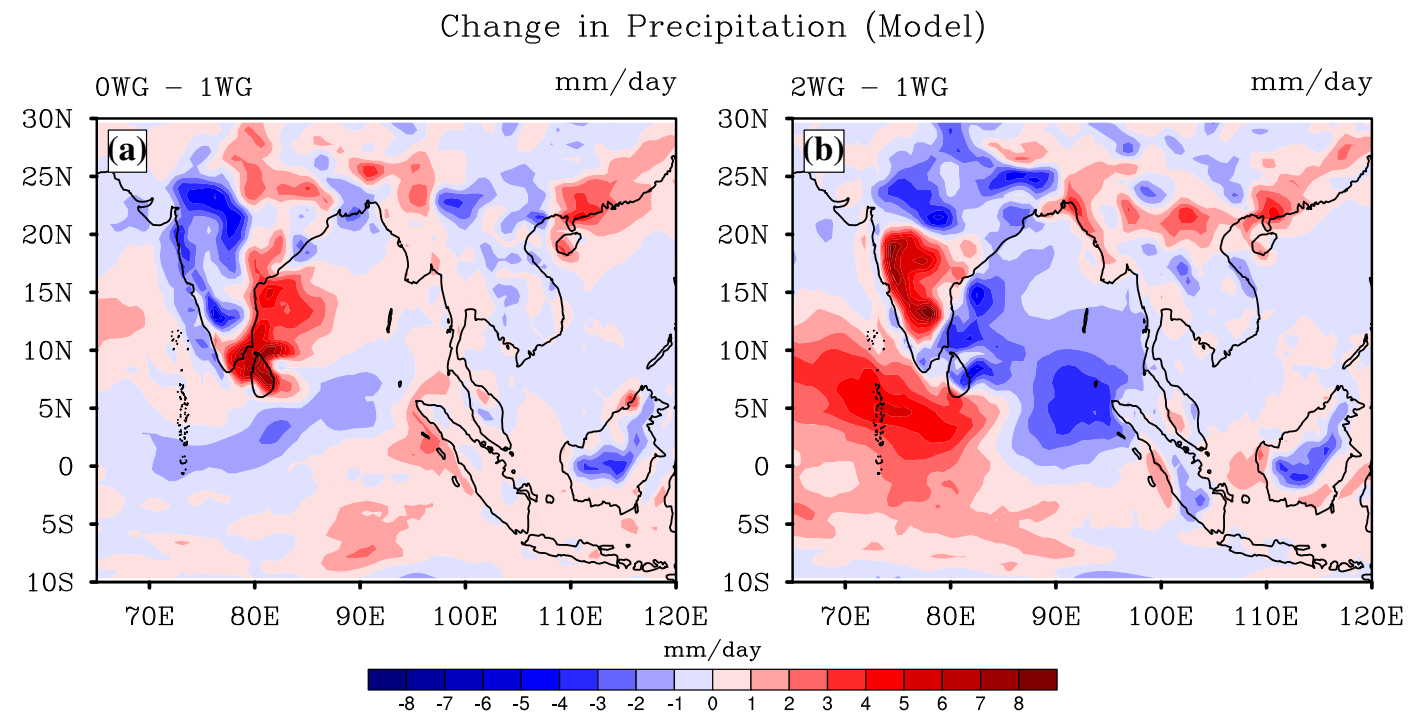

Figure 7. Change in the JJAS rainfall with the change in height of the WG mountains. (a) $0 \mathrm{WG}-1 \mathrm{WG}$ and (b) $2 \mathrm{WG}-1 \mathrm{WG}$.

increases by about $15 \%$ with an increase in the height of the WG from zero to double its present height.

The impact of the height of the WG on the BoB$\mathrm{CP}$ rainfall during summer can also be seen in the JJAS mean area averaged rainfall (figure 8). There is a decrease in the rainrate over the BoB-CP with an increase in the height of the WG from $0 \mathrm{WG}$ to $2 \mathrm{WG}$. This change is from 9.3 (0WG) to $4.1 \mathrm{~mm}$ day $^{-1}$ (2WG). Thus, when the height of the WG increases from zero to double its present height, the rainfall decreases by $56 \%$. This clearly depicts the importance of the WG mountains in modulating the rainrate over the $\mathrm{BoB}-\mathrm{CP}$. In the following paragraphs, we investigate the reason behind this strong relationship between the height of the WG and the rainfall over the BoB-CP.

\subsection{Modulation of atmospheric circulation}

The longitude-height cross section of vertical pressure velocity which was averaged over $8^{\circ}-10^{\circ} \mathrm{N}$ latitudes for the three simulations, is shown in figure 9. The longitudinally extended wave train of ascent and descent, as seen in the observation (figure 3), is captured by the model. It is clear that with an increase in the height of the WG, the ascent 
Cold Pool Precipitation :: JJAS

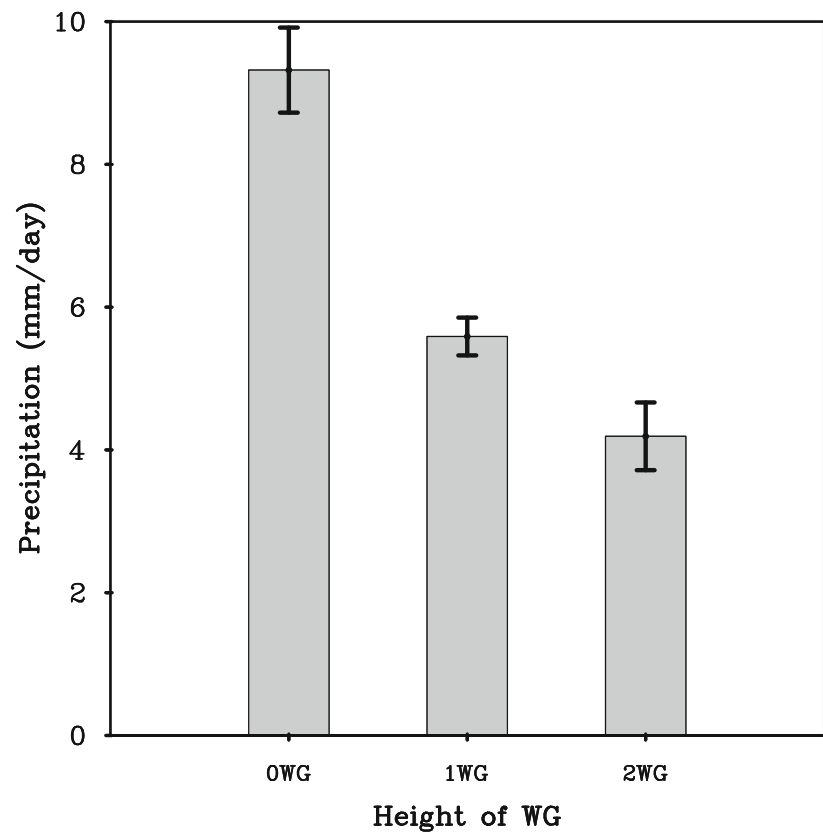

Figure 8. The JJAS rainfall climatology over the cold pool with modified height of the WG mountains. The error bars show one standard deviation within the 10-year simulation.

and descent increase in strength with no change or an insignificant one in the wavelength. In the $0 \mathrm{WG}$ case, we still observe a wave pattern that resembles a lee wave. However, this is not associated with the lee waves from the WG, but are possibly created because of the Sri Lankan orography. This wave is not as strong as the wave created by the WG. However, the increase in the height of the WG makes the lee waves stronger, produces greater descent over the BoB-CP and makes the region less favourable for convection and rainfall.

The vertical profile of vertical velocity averaged over the BoB-CP region in figure 10(b) shows an ascent above about $650 \mathrm{hPa}$ and a descent closer to the surface. We also observe that the level at which the transition from a descent to an ascent occur rises in the presence of the WG orography, but is largely insensitive to its height. For example, between $0 \mathrm{WG}$ and $1 \mathrm{WG}$, there is an increase in the height of transition from 850 to $650 \mathrm{hPa}$. However, a further increase in the height of the WG has no effect on the height of this level of transition.

The strengthening of the lee waves and the resulting inhibition of convection over the BoB-CP can also be understood by analysing the variations in surface moisture convergence and vertical moisture flux above the boundary layer. Figure 10(a) shows the vertical profile of the horizontal moisture
MEAN (JJAS) Vertical Velocity [Avg lon : $6^{\circ} \mathrm{N}-11^{\circ} \mathrm{N}$ ]
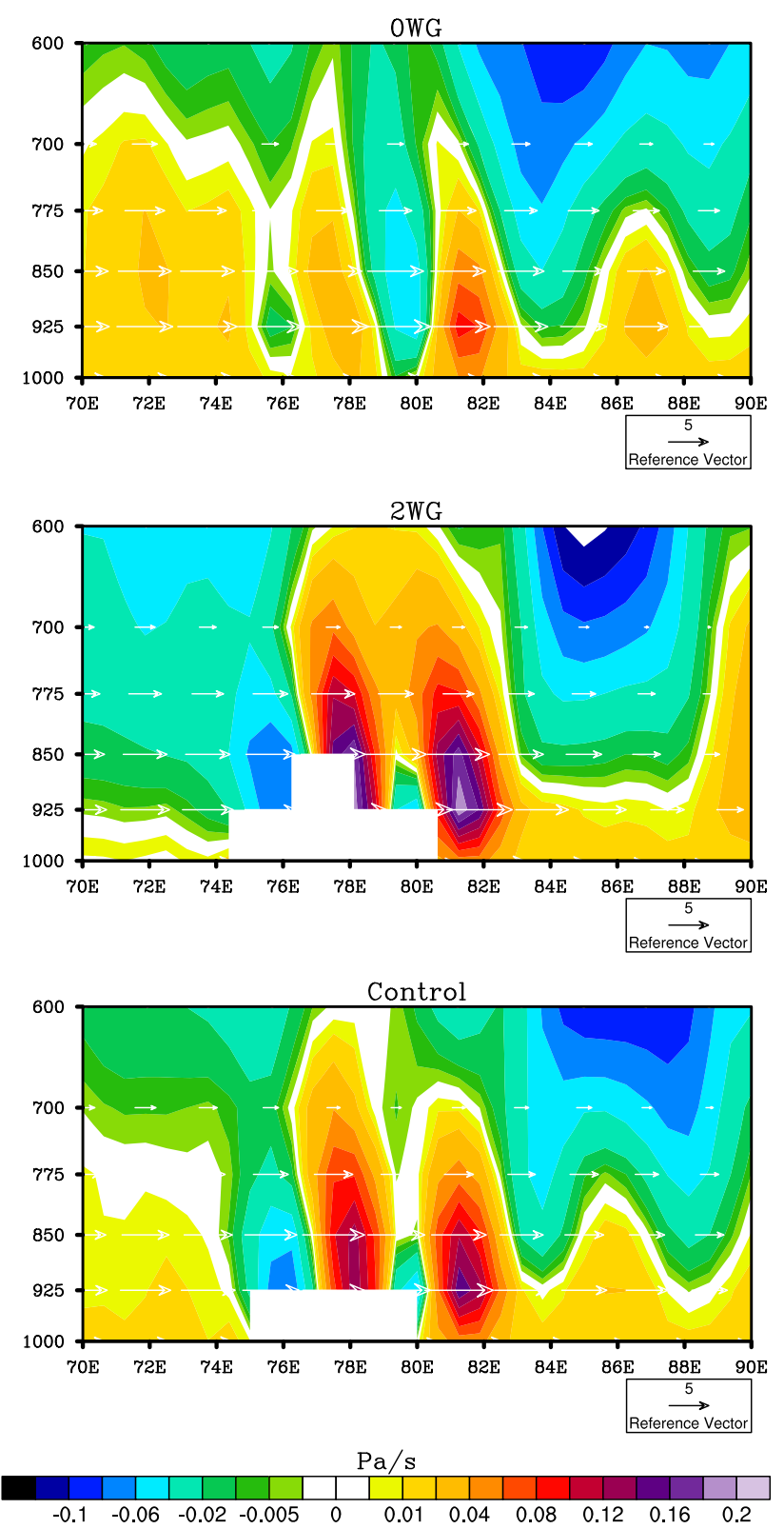

Figure 9. Increase in strength of lee waves with an increase in the height of the WG averaged between $8^{\circ}$ and $10^{\circ} \mathrm{N}$. The blank area between $76^{\circ}$ and $78^{\circ} \mathrm{E}$ represents a part of the WG orography. The arrows represent zonal wind vectors averaged along the same latitudes.

convergence over the BoB-CP for simulations with different heights of the WG. The moisture convergence in the boundary layer (from 1000 to 925 $\mathrm{hPa}$ ) increases with a decrease in the height of the WG. However, above the boundary layer, there is a decrease in the moisture convergence with increase in the height of the WG. The surface moisture convergence changes its sign from positive (0WG) to negative (1WG) (figure 11). In the case of $0 \mathrm{WG}$, the positive surface moisture convergence increases 


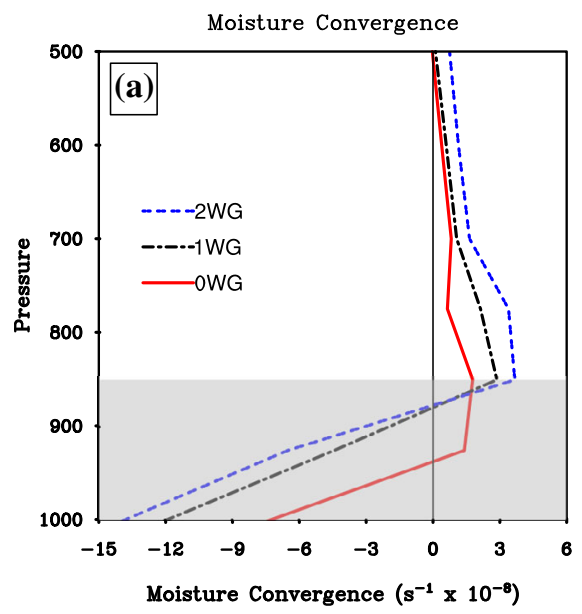

JJAS Climatology - Cold Pool (Model)
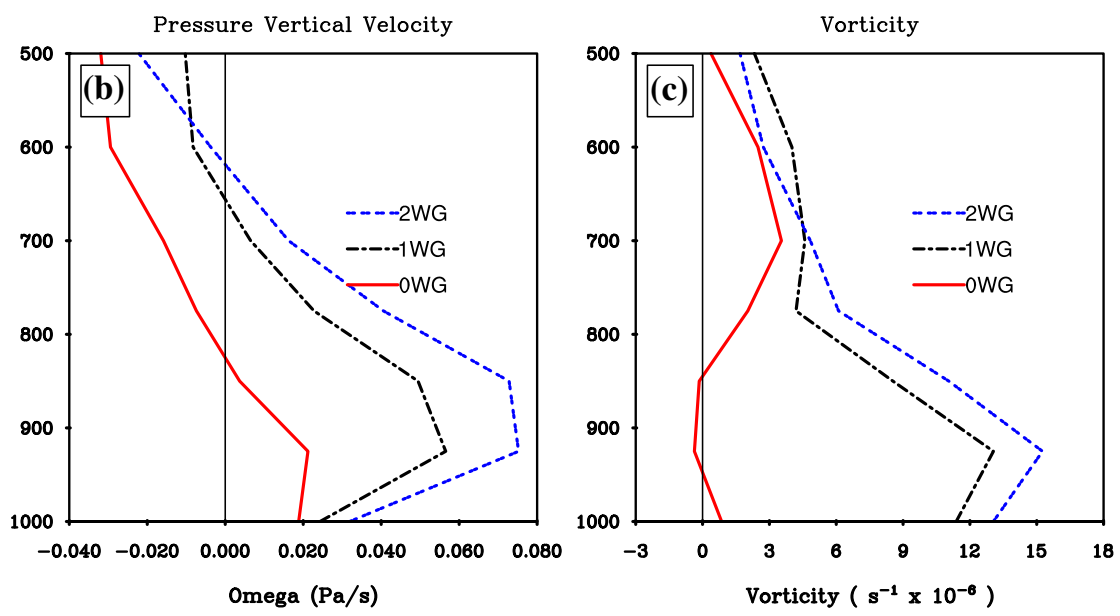

Figure 10. The June-September mean vertical profile of (a) moisture convergence, (b) pressure vertical velocity (omega) and (c) vorticity with the increased height of the WG mountains. The shaded area in (a) represents the vertical extend used for the calculation of moisture convergence in the boundary layer.

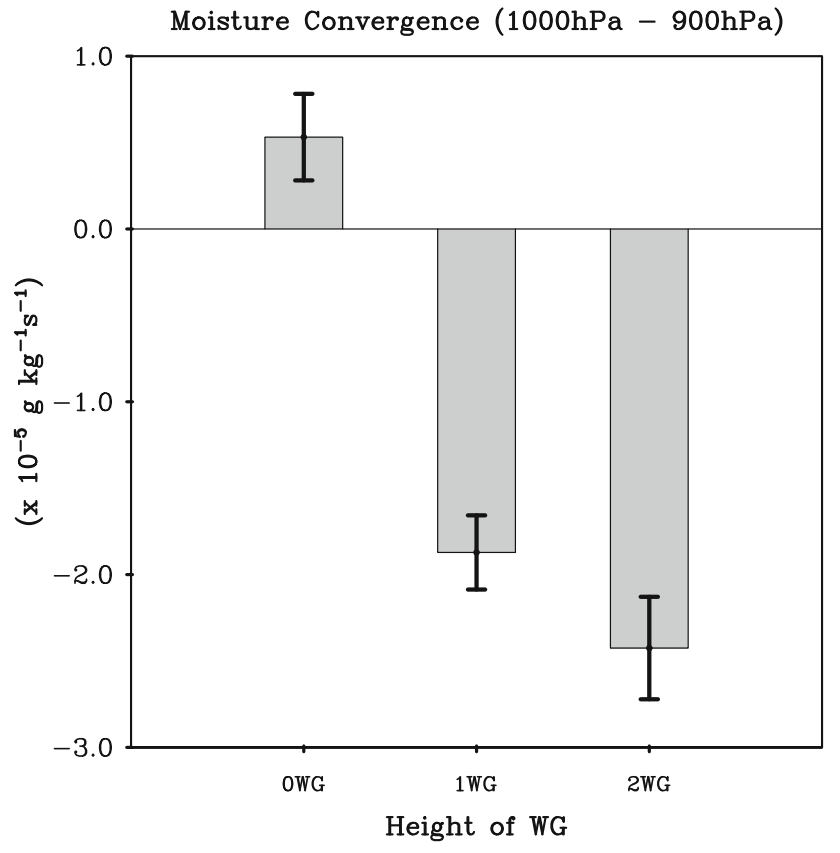

Figure 11. The variation of the June-September mean surface moisture convergence (from 1000 to $900 \mathrm{hPa}$ ) with increase in the height of the WG. The standard deviation within the 10-year simulation is indicated by error bars.

the availability of moisture for convection over the BoB-CP. This moisture is absent when the orography is present in the simulation.

There is also a reduction in vertical moisture flux above the boundary layer with an increase in the height of the WG. We chose the $775 \mathrm{hPa}$ layer to determine the effect of the mountain height on the vertical velocity (figure 12a) and the vertical moisture flux (figure 12b) above the boundary layer. This level was chosen because the variations in these quantities are more evident at this level. We find a transition from unfavourable (descent) to favourable (ascent) vertical velocities for convection at $775 \mathrm{hPa}$ with the removal of the WG. The magnitude of descent appears to be related to the height of the mountains. Similarly, the vertical moisture flux is positive in the absence of the WG and becomes negative in its presence (figure $12 \mathrm{~b}$ ). We also note that the presence or absence of the WG orography has a larger impact on these parameters than further changes in its height. With low-level moisture convergence and favourable (upward) moisture flux above the boundary layer, convection occurs over the BoB$\mathrm{CP}$ in the absence of the WG.

In the observations, we find a positive vorticity over the BoB-CP (figure 1) despite the absence of rainfall. Similar values of vorticity can be seen in the model and these values increase with an increase in the height of the WG (figure 10c). Generally, cyclonic vorticity above the boundary layer is associated with convection and rainfall. This seemingly anomalous behaviour could be associated with the large scale circulation that is strongly influenced by monsoonal rainfall. Figure 13 shows the changes in wind vectors over the western, southern and eastern parts of the southern peninsula in different experiments. Over the western side, the winds become more southward with an increase in the height of the WG. The winds become more zonal and northward over the 
JJAS Climatology
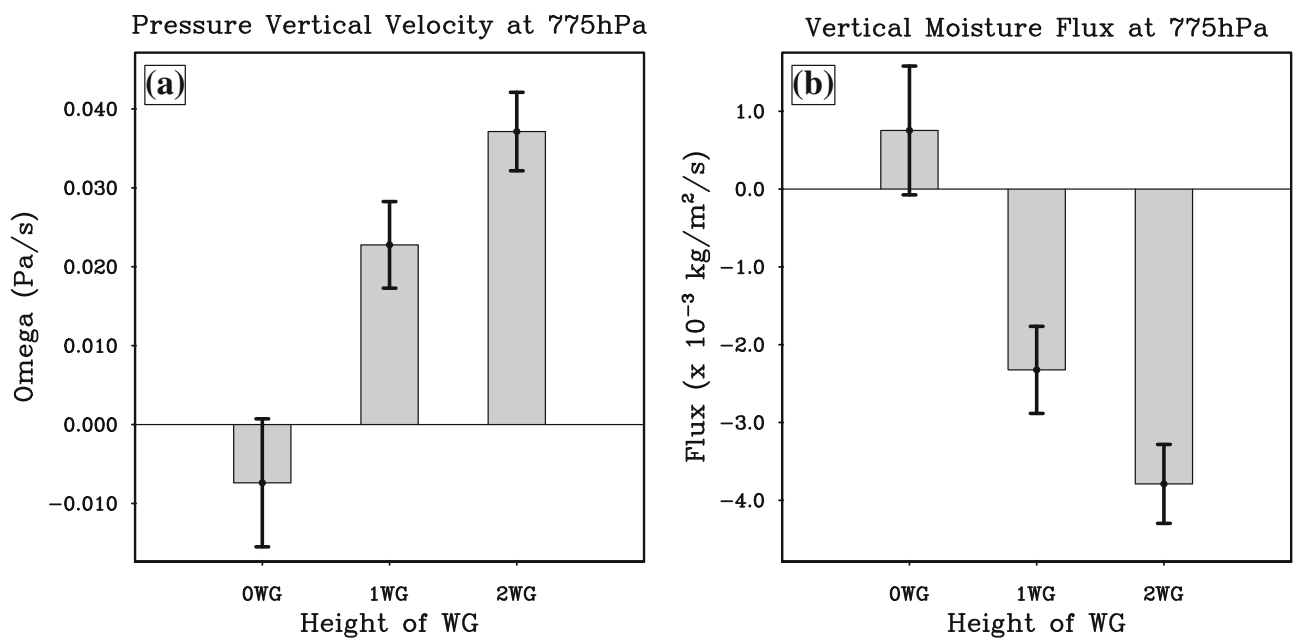

Figure 12. The change in the June-September mean pressure vertical velocity (775 hPa) and vertical moisture flux above the boundary layer $(775 \mathrm{hPa})$ with the increased height of the WG. The error bars show one standard deviation within the 10-year simulation.

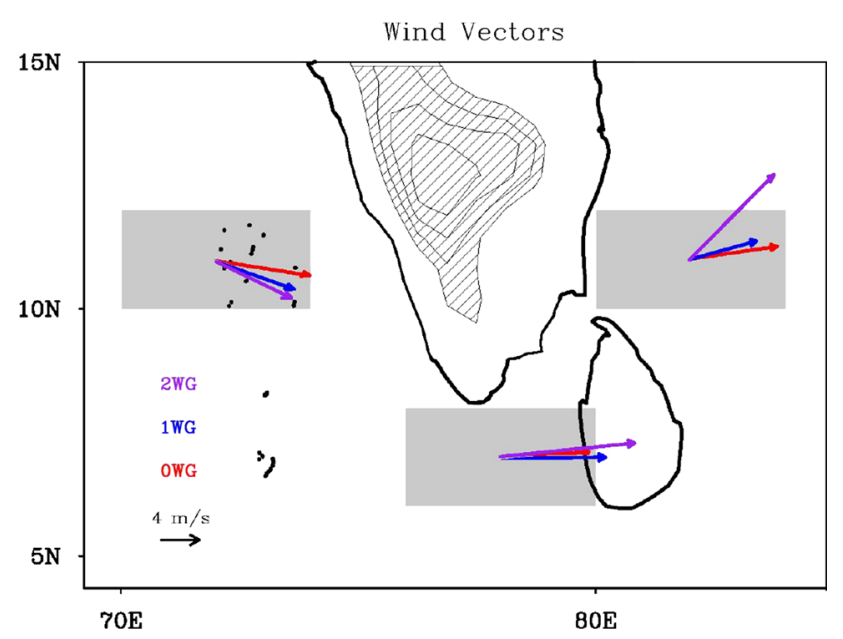

Figure 13. Change in wind direction over west, south and east side of the southern peninsula with the increased height of the WG. With the increase in height of the WG, the winds are trying to go around the mountains. The hatched area represents the WG.

southern side of the peninsula and become more northward over the eastern side. This shows that as the height of the WG increases, the winds tend to go around the mountains rather than above them. So, the increase in vorticity could be because of the large scale circulation that becomes more cyclonic near the southern side of the peninsula with an increase in the height of the WG. As the boundary over this region is of the 'well-mixed' variety rather than an Ekman layer, Ekman pumping may not play a significant role in modulating convection.

\subsection{Impact on the seasonal cycle of rainfall}

It was observed in figure 4 that the seasonal variation of rainfall over the $\mathrm{BoB}-\mathrm{CP}$ is different than that over Inland. While the rainfall over India has a single and strong peak in July, the BoB$\mathrm{CP}$ experiences two peaks, one in May (secondary) and the other in November (primary). The control model (1WG) captures the annual cycle of the rainrate over the BoB-CP fairly well except that the peak in November gets shifted to DecemberJanuary. The variation in the heights of the WG changes the annual cycle of rainfall over the BoB$\mathrm{CP}$ (figure 14). When we remove the WG, the annual cycle of rainfall over the BoB-CP shifts closer to that of Inland, but with a peak in June instead of in July. This early peak in the monsoon over the BoB-CP in 0WG could be because of the southward location of the region compared to the Indian landmass. In the case of $2 \mathrm{WG}$, the annual cycle of rainfall over the BoB-CP comes close to that in the observations with a prominent peak in December. Therefore, the presence of orography plays a crucial role in determining the annual cycle of rainfall over the BoB-CP, which is different from that over Inland. In the absence of the WG orography, the annual cycle of the rainrate over the BoB-CP becomes closer to that over India.

\subsection{Impact on the winter monsoon}

Finally, we study the role of the WG mountains on the winter climate of BoB-CP. This is particularly relevant since we noted in figure 14, that 


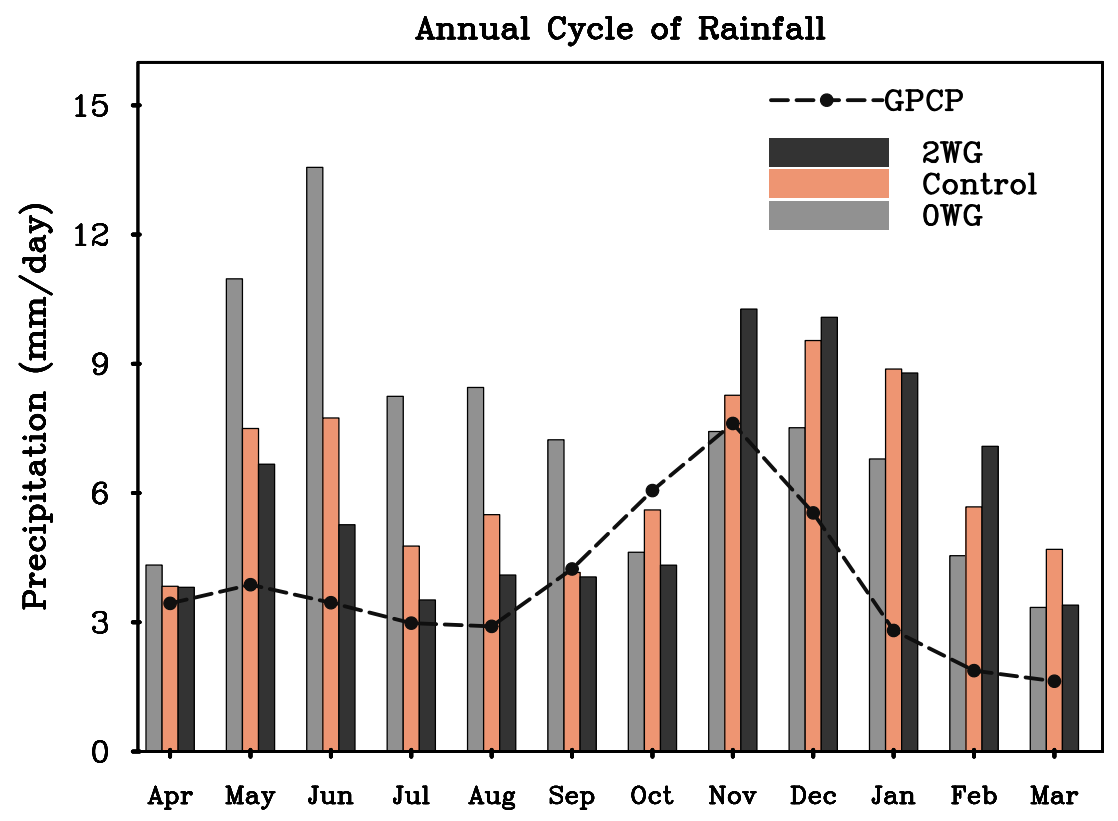

Figure 14. The annual cycle of rainfall over the cold pool for the three simulations and the observations (GPCP). The black dots are the values for the observation. From $2 \mathrm{WG}$ to $0 \mathrm{WG}$, the primary peak in the annual cycle of rainfall changes from November to June.

\section{NDJF - Precipitation}
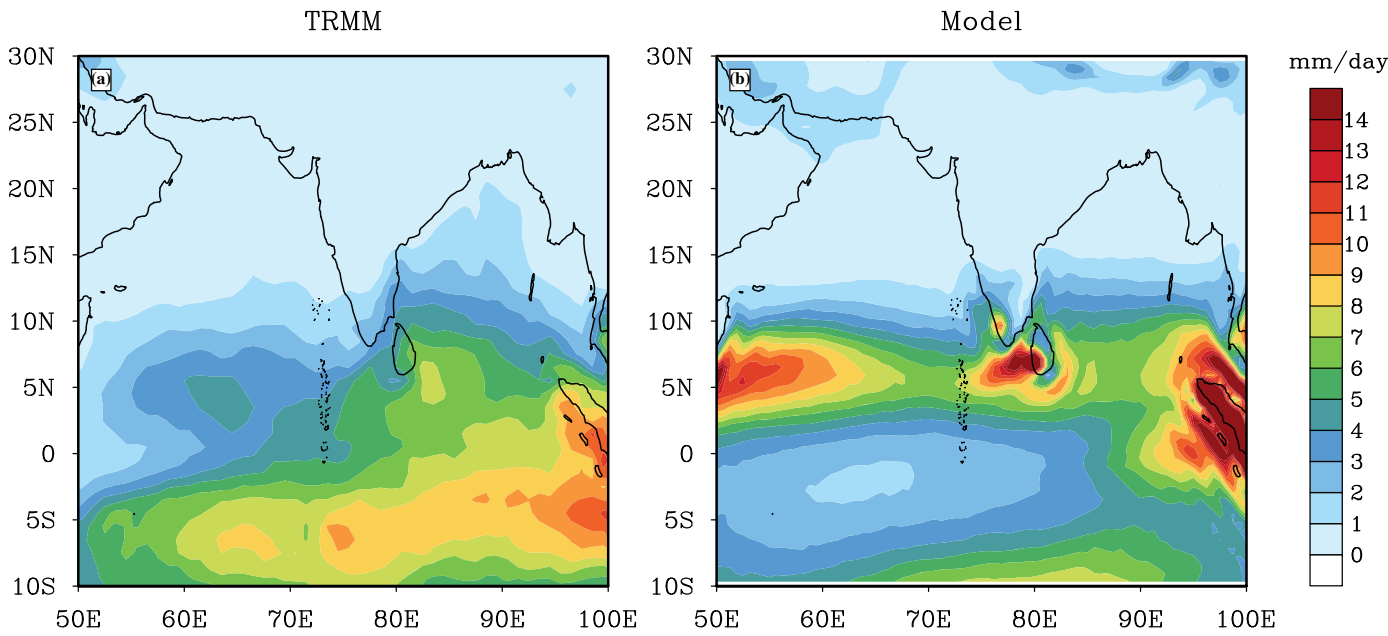

Figure 15. Climatology of November-February mean rainfall from (a) observation and (b) model.

in the absence of the WG orography, the seasonal cycle of rainfall over the BoB-CP resembles that over Inland. In the boreal winter, the surface winds over the Indian region reverse direction from southwesterly to northeasterly. This is also the season when, in the observations, the BoB-CP and southern peninsular India receive the maximum rainfall. In the model with the present height of the WG (1WG), the peak in rainfall over the BoB-CP is during the winter season, analogous to the observation. The spatial pattern of rainfall over south Asia (in the model) shows two zonally oriented bands of rainfall, one north of the equator and the other south of the equator. In contrast, we find a single rain band along $5^{\circ} \mathrm{S}$ in the observations (figure 15).

It is seen that the climatology of rainfall over the BoB-CP during this season increases with an increase in height of the WG (figure 16;6.6 $\mathrm{mm}$ day $^{-1}$ in $0 \mathrm{WG}$ to $9.1 \mathrm{~mm}$ day $^{-1}$ in $2 \mathrm{WG}$ ). The winds hit the eastern boundary of WG causing rainfall along the eastern region of peninsular India; this includes the BoB-CP as well. In addition to the WG, the Sri Lankan orography also contributes to the total rainfall over 
Cold Pool Precipitation :: NDJF

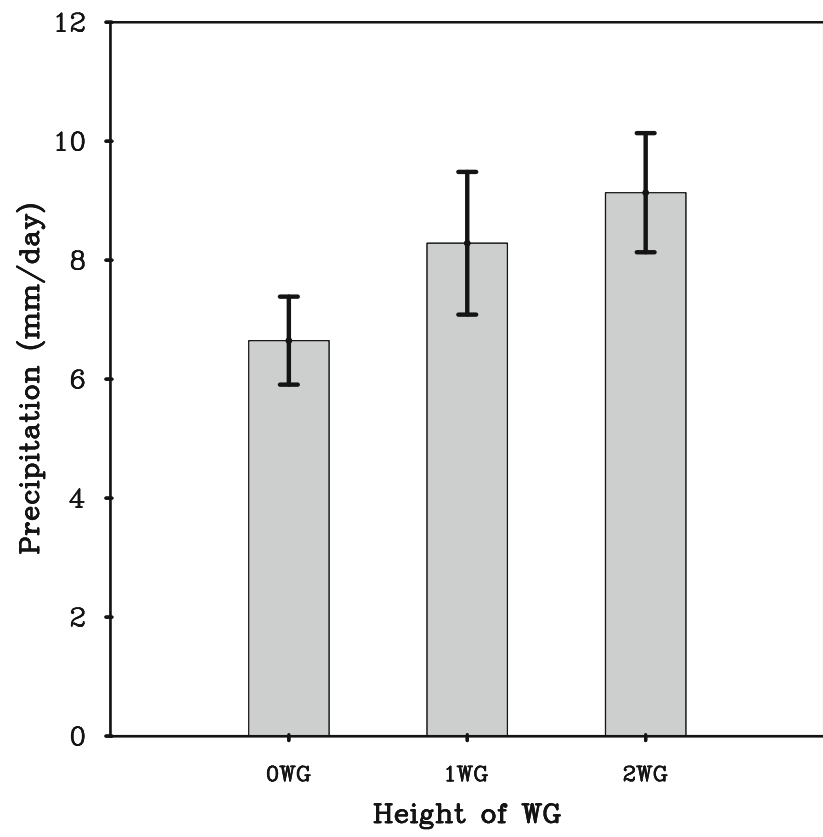

Figure 16. Winter monsoon rainfall climatology over cold pool with the increased height of WG. Rainfall increases from OWG to $2 \mathrm{WG}$. Error bars showing one standard deviation within the 10-year simulation are also indicated.

BoB-CP during this season. However, in the absence of WG, the orographic influence vanishes resulting into reduced precipitation over BoB-CP, while in the $2 \mathrm{WG}$ simulations, the associated circulation changes induce more rainfall over BoB-CP. When the height of the WG doubled, winds are blocked and split into two branches and tend to move around the mountains; one moves southwards and the other moves northwards going around the mountains and forms more cyclonic circulation to the north of the WG boundary (not shown). The southern branch, carrying enough moisture along its way favours more precipitation over the southeastern coast of peninsular India, increasing precipitation over BoB-CP.

\subsection{Influence of the $W G$ on the global upper-tropospheric circulation}

Even though the WG mountains are narrow and limited to a very small latitudinal range, they influence the upper tropospheric circulation throughout the globe. Figures 17 and 18 show the changes in the $200 \mathrm{hPa}$ zonal and meridional circulations in the Northern Hemisphere during JJAS (JuneJuly-August-September) and NDJF (NovemberDecember-January-February) seasons, respectively.
The north Atlantic Ocean and North America show considerable changes in the upper tropospheric circulation in both $2 \mathrm{WG}$ and $0 \mathrm{WG}$ (figure 17) simulations during JJAS season. A flip in the sign of zonal wind anomaly is noticed from north Atlantic Ocean to the east coast of North America (from 2WG to $0 \mathrm{WG}$ ); the anomalies over Pacific Ocean do not vary with the change in height of WG. In the case of meridional wind anomaly, influence of mountains is stronger. The $2 \mathrm{WG}$ case, shows changes across the northern hemisphere; mainly over the east coast of north Atlantic Ocean, the Mediterranean Sea, North America and central Asia, the meridional wind anomaly changes from positive to negative when the height of the WG dropped to zero.

The NDJF season shows a prominent shift of the mid-latitude westerly jet in the Northern Hemisphere from $2 \mathrm{WG}$ to $0 \mathrm{WG}$; the core of the jet over the Atlantic and the east Pacific regions seems to shift northward in the $2 \mathrm{WG}$ case. In the zonal direction, the maxima in the jet has shifted to the western hemisphere from the eastern hemisphere.

This shifting of the westerly jet in both the zonal and meridional directions could influence the overall climate of the respective regions. The upper tropospheric temperatures also vary from their control values with changes in the height of the WG. Consequently, in response to the shift in upper tropospheric circulation, the lower troposphere shows anomalies in the circulation pattern (not shown). However, these changes are not directly reflected in the rainfall patterns over higher latitudes as this rainfall is not as high as that over tropical regions. Recent study by Petoukhov et al. (2016a,b) showed that occurrence of many of the extreme weather events of the past decade in the Northern Hemisphere mid-latitudes have been associated with the quasi-stationary planetary waves within the same hemisphere. Thus, variation in height of WG and the consequent changes in the mean upper tropospheric flow has rather crucial role in changing the climate over those latitudes. It is intriguing that a very narrow mountain near the tropics can cause large variations in circulation in the higher latitudes. We plan to investigate the detailed mechanism of this association in future.

\section{Summary}

During the boreal summer a region along the southeastern coast of peninsular India, referred to as 
Change in $u$-wind $(200 h P a)::$ JJAS
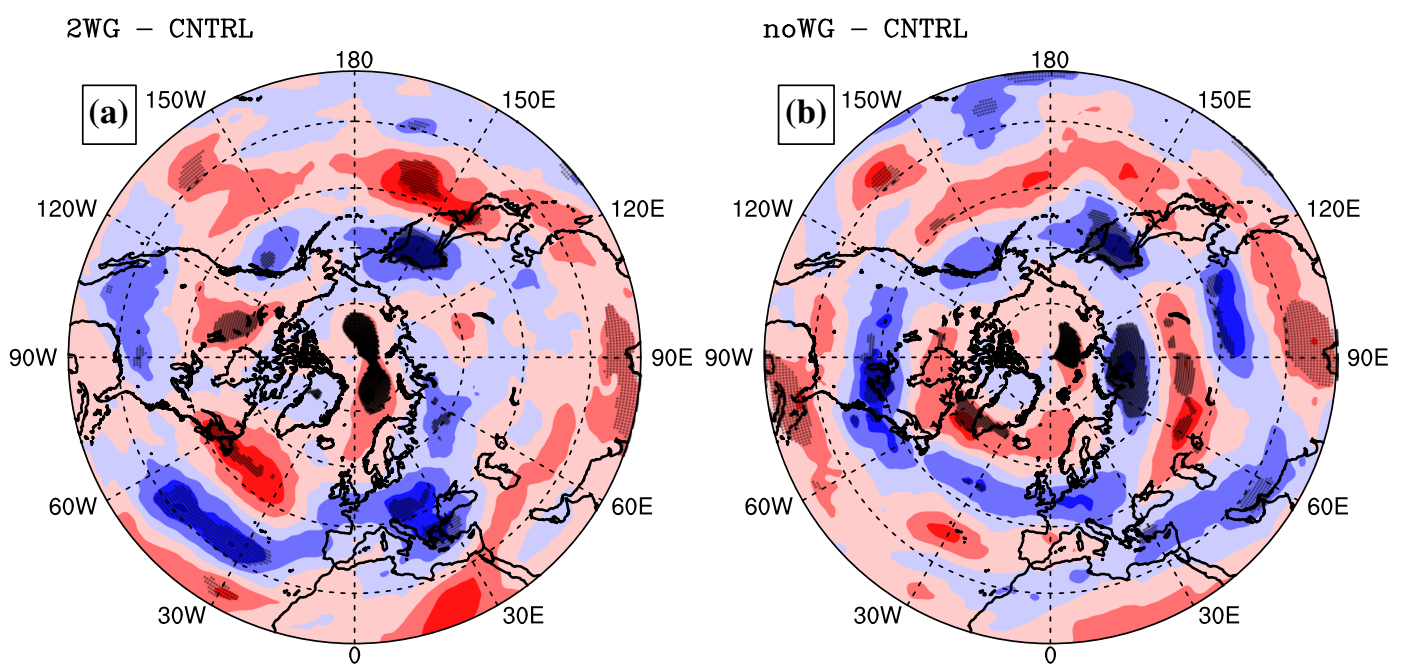

Change in $\mathrm{v}$-wind $(200 \mathrm{hPa})::$ JJAS
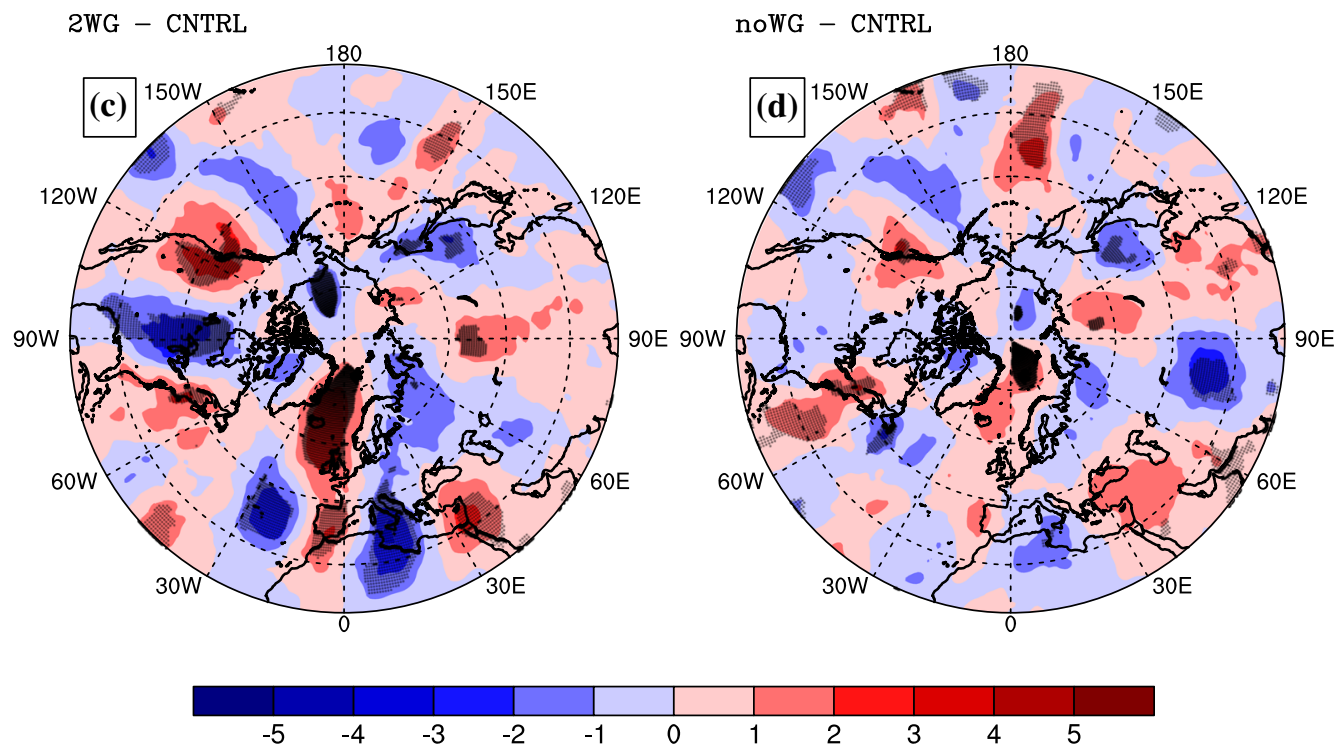

Figure 17. Changes in $200 \mathrm{hPa}$ winds as compared to control: (a) zonal winds in 2WG, (b) zonal winds in 0WG, (c) meridional winds in $2 \mathrm{WG}$ and (d) meridional winds in $0 \mathrm{WG}$ in JJAS season. The shaded areas are for the values within 95 percentile confidence interval.

the $\mathrm{BoB}-\mathrm{CP}$ in this study, receives scanty rainfall compared to its surroundings. While the conditions such as SST and lower tropospheric vorticity over this region stay favourable for convection, the vertical velocity and moisture convergence in the boundary layer prevent convection. Additionally, an east-west elongated wave like-pattern in the vertical velocity is noticed over the region. This wave is observed along the leeward side of the WG and seems to be generated on account of the interaction of strong near-surface westerlies with the WG. We hypothesize that since the BoB-CP region falls under the descending branch of this wave, it receives scanty amounts of rainfall in the boreal summer. This hypothesis is tested with perturbed orography simulations using an AGCM; three experiments (duration: 10 years) were performed. The first one is without the WG mountains (0WG). The second one keeps the present height of the WG (1WG or control). In the third one, the height of the mountains is doubled from its present value (2WG). The rainfall over the BoB-CP in the JJAS season decreases from $9.3 \mathrm{~mm}$ day $^{-1}$ in the $0 \mathrm{WG}$ to $4.1 \mathrm{~mm}$ day $^{-1}$ in the $2 \mathrm{WG}$ experiments. It 

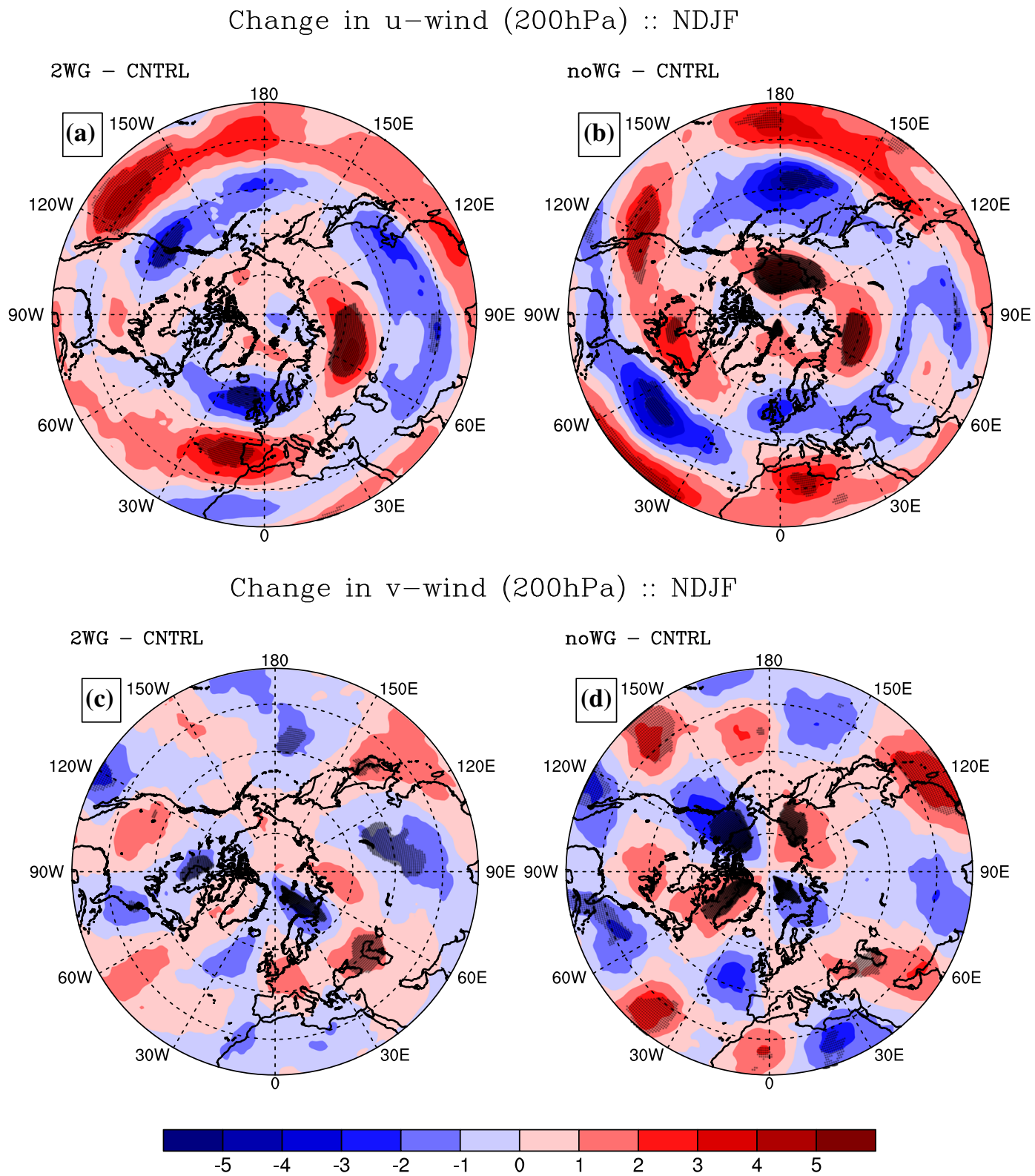

Figure 18. Changes in $200 \mathrm{hPa}$ winds as compared to control: (a) zonal winds in 2WG, (b) zonal winds in 0WG, (c) meridional winds in $2 \mathrm{WG}$ and (d) meridional winds in $0 \mathrm{WG}$ in NDJF season. The shaded areas are for the values within 95 percentile confidence interval.

is seen that this decrease in rainfall with increased mountain height is associated with an enhanced descent and boundary layer divergence over the $\mathrm{BoB}-\mathrm{CP}$. A decrease in moisture convergence in the boundary layer gives rise to a reduction in vertical moisture flux above the boundary layer, which eventually decreases convection.

In addition to the summer monsoon, the presence of the WG mountains also changes the seasonal cycle of rainfall over the BoB-CP; without the mountains, the seasonal cycle follows that over Inland. The $1 \mathrm{WG}$ and $2 \mathrm{WG}$ simulations show seasonal monsoon peaks during the winter season. This is consistent with the gradual increase in rainfall over the BoB-CP in winter with increase in the WG height.

In this study, we show the importance of the WG mountains in determining the regional climate. The results suggest that an adequate representation of narrow mountains is necessary in the numerical models that are used to understand and predict the monsoon over south Asia. The study also suggests 
that a narrow mountain of a very small latitudinal range in the tropics can change the circulation at higher latitudes.

\section{Acknowledgements}

R S Nanjundiah acknowledges the support from INCOIS (Indian National Centre for Ocean Information Services) under HOOFS (High-resolution Operational Ocean Forecast and reanalysis System) programme for this research. The National Monsoon Mission (NMM) and CTCZ (Continental Tropical Convergence Zone) programme of Ministry of Earth Sciences (MoES) are acknowledged by A Chakraborty and R S Nanjundiah for their financial support.

\section{References}

Bolin B 1950 On the influence of the Earth's orography on the general character of the westerlies; Tellus $A \mathbf{2 ( 3 )}$ 184-195.

Boos W R and Kuang Z 2010 Dominant control of the South Asian Monsoon by orographic insulation versus plateau heating; Nature 463(7278) 218-222.

Broccoli A and Manabe S 1992 The effects of orography on midlatitude Northern Hemisphere dry climates; J. Clim. 5(11) 1181-1201.

Bruce J G, Johnson D R and Kindle J C 1994 Evidence for eddy formation in the eastern Arabian Sea during the northeast monsoon; J. Geophys. Res. Oceans (1978-2012) 99(C4) 7651-7664.

Chakraborty A, Nanjundiah R and Srinivasan J 2002 Role of Asian and African orography in Indian summer monsoon; Geophys. Res. Lett. 29(20) 50-1-50-4.

Chakraborty A, Nanjundiah R and Srinivasan J 2006 Theoretical aspects of the onset of Indian summer monsoon from perturbed orography simulations in a GCM; Ann. Geophys. 24(8) 2075-2089.

Chakraborty A, Nanjundiah R S and Srinivasan J 2009 Impact of African orography and the Indian summer monsoon on the low-level Somali jet; Int. J. Climatol. 29(7) 983-992.

Chou M D 1992 A solar radiation model for use in climate studies; J. Atmos. Sci. 49(9) 762-772.

Chou M D and Lee K T 1996 Parameterizations for the absorption of solar radiation by water vapor and ozone; J. Atmos. Sci. 53(8) 1203-1208.

Chou M D and Suarez M J 1999 A solar radiation parameterization for atmospheric studies; NASA Technical Memo 104606:40.

Corby G and Wallington C 1956 Airflow over mountains: The lee-wave amplitude; Quart. J. Roy. Meteorol. Soc. 82(353) 266-274.

Durran D R and Klemp J B 1982 The effects of moisture on trapped mountain lee waves; J. Atmos. Sci. 39(11) 2490-2506.
Ek M, Mitchell K, Lin Y, Rogers E, Grunmann P, Koren V, Gayno G and Tarpley J 2003 Implementation of NOAH land surface model advances in the National Centers for Environmental Prediction operational mesoscale ETA model; J. Geophys. Res. Atmos. (1984-2012) 108(D22).

Findlater J 1969 A major low-level air current near the Indian Ocean during the northern summer; Quart. J. Roy. Meteorol. Soc. 95(404) 362-380.

Gadgil S, Joseph P V and Joshi N V 1984 Ocean-atmosphere coupling over monsoon regions; Nature 312(5990) 141143, https://doi.org/10.1038/312141a0.

Graham N and Barnett T 1987 Sea surface temperature, surface wind divergence, and convection over tropical oceans; Science 238(4827) 657-659.

Hahn D G and Manabe S 1975 The role of mountains in the south Asian monsoon circulation; J. Atmos. Sci. 32(8) 1515-1541.

He H, McGinnis J W, Song Z and Yanai M 1987 Onset of the Asian Summer Monsoon in 1979 and the effect of the Tibetan Plateau; Mon. Wea. Rev. 115(9) 1966-1995.

Hou Y, Moorthi S and Campana K 2002 Parameterization of solar radiation transfer in the NCEP models; NCEP Office Note 441 1-46.

Huffman G J, Bolvin D T, Nelkin E J, Wolff D B, Adler $\mathrm{R}$ F, Gu G, Hong Y, Bowman K P and Stocker E F 2007 The TRMM multisatellite precipitation analysis (TMPA): Quasi-global, multiyear, combined-sensor precipitation estimates at fine scales; J. Hydrometeor. 8(1) $38-55$.

Joseph P, Sooraj K, Babu C and Sabin T 2005 A cold pool in the Bay of Bengal and its interaction with the activebreak cycle of the Monsoon; Clivar Exch. 34(10) 3.

Krishnamurti T, Molinari J and Pan H 1976 Numerical simulation of the Somali jet; J. Atmos. Sci. 33.

Luo H and Yanai M 1983 The large-scale circulation and heat sources over the Tibetan Plateau and surrounding areas during the early Summer of 1979. Part I: Precipitation and kinematic analyses; Mon. Wea. Rev. 111(5) 922-944.

Luo H and Yanai M 1984 The large-scale circulation and heat sources over the Tibetan Plateau and surrounding areas during the early Summer of 1979. Part II: Heat and moisture budgets; Mon. Wea. Rev. 112(5) 966-989.

Manabe S and Terpstra T B 1974 The effects of mountains on the general circulation of the atmosphere as identified by numerical experiments; J. Atmos. Sci. 31(1) 3-42.

Meehl G 1992 Effect of tropical topography on global climate; Ann. Rev. Earth Planet. Sci. 2085.

Mlawer E J, Taubman S J, Brown P D, Iacono M J and Clough S A 1997 Radiative transfer for inhomogeneous atmospheres: RRTM, a validated correlated-k model for the longwave; J. Geophys. Res. Atmos. (19842012) 102(D14) 16,663-16,682.

Moorthi S and Suarez M J 1992 Relaxed Arakawa-Schubert. A parameterization of moist convection for general circulation models; Mon. Wea. Rev. 120(6) 978-1002.

Petoukhov V, Coumou D, Rahmstorf S, Stadtherr L, Kornhuber K, Petri S and Schellnhuber H J 2016a Extreme events of 2012, 2013 and 2014 linked to planetary wave resonance; In: EGU General Assembly Conference Abstracts, 18, p. 5426.

Petoukhov V, Petri S, Rahmstorf S, Coumou D, Kornhuber K and Schellnhuber H J 2016b Role of quasiresonant 
planetary wave dynamics in recent boreal spring-toautumn extreme events; Proceedings of the National Academy of Sciences.

Rao R, Kumar G, Ravichandran M, Samala B and Sreedevi N 2006 Observed mini-cold pool off the southern tip of India and its intrusion into the south central Bay of Bengal during summer monsoon season; Geophys. Res. Lett. $33(6)$.

Reynolds R W, Rayner N A, Smith T M, Stokes D C and Wang W 2002 An improved in situ and satellite SST analysis for climate; J. Clim. 15(13) 1609-1625, https://doi. org/10.1175/1520-0442(2002)015〈1609:AIISAS $\rangle 2.0$. CO;2.

Rienecker M M, Suarez M J, Gelaro R, Todling R, Bacmeister J, Liu E, Bosilovich M G, Schubert S D, Takacs L and Kim G K et al. 2011 MERRA: NASA's modern-ERA retrospective analysis for research and applications; J. Clim. 24(14) 3624-3648.

Shankar D and Shetye S 1997 On the dynamics of the Lakshadweep high and low in the southeastern Arabian Sea; J. Geophys. Res. Oceans (1978-2012) 102(C6) 12,55112,562 .

Shankar D, Shetye S and Joseph P 2007 Link between convection and meridional gradient of sea surface temperature in the Bay of Bengal; J. Earth Syst. Sci. 116(5) 385-406.

Corresponding editor: AsHoK KARUMURI
Shenoi S, Shankar D and Shetye S 2002 Differences in heat budgets of the near-surface Arabian Sea and Bay of Bengal: Implications for the summer monsoon; J. Geophys. Res. Oceans (1978-2012) 107(C6) 5-1.

Sijikumar S, John L and Manjusha K 2013 Sensitivity study on the role of Western Ghats in simulating the Asian summer monsoon characteristics; Meteor. Atmos. Phys. 120(1-2) 53-60.

Slingo J, Spencer H, Hoskins B, Berrisford P and Black E 2005 The meteorology of the Western Indian Ocean, and the influence of the East African Highlands; Philos. Trans. Roy. Soc. London A: Math. Phys. Eng. Sci. 363(1826) $25-42$.

Wang B 2002 Rainy season of the Asian-Pacific summer monsoon; J. Clim. 15(4) 386-398.

Wu G and Zhang Y 1998 Tibetan Plateau forcing and the timing of the monsoon onset over south Asia and the South China Sea; Mon. Wea. Rev. 126(4) 913-927.

Xie S P, Xu H, Saji N H, Wang Y and Liu W T 2006 Role of narrow mountains in large-scale organization of Asian Monsoon convection; J. Clim. 19(14) 3420-3429, https:// doi.org/10.1175/JCLI3777.1.

Ye D 1981 Some characteristics of the summer circulation over the Qinghai-Xizang (Tibet) Plateau and its neighborhood; Bull. Am. Meteorol. Soc. 62(1) 14-19. 